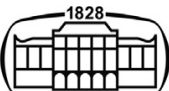

AKADÉMIAI KIADÓ

Journal of Behavioral Addictions

9 (2020) 2, 184-186

DOI:

$10.1556 / 2006.2020 .00016$

(c) 2020 The Author(s)

\title{
Problematic online gaming and the COVID-19 pandemic
}

\author{
DANIEL L. KING ${ }^{* 1} \odot$, PAUL H. DELFABBRO ${ }^{2}$, JOEL BILLIEUX ${ }^{3}$ \\ and MARC N. POTENZA ${ }^{4}$ \\ ${ }^{1}$ College of Education, Psychology and Social Work, Flinders University, Adelaide, SA, Australia \\ ${ }^{2}$ School of Psychology, The University of Adelaide, Adelaide, SA, Australia \\ ${ }^{3}$ University of Lausanne, Lausanne, Switzerland \\ ${ }^{4}$ Departments of Psychiatry and Neuroscience, Child Study Center, Yale University School of \\ Medicine, New Haven, CT, USA
}

Received: April 06, 2020 • Revised manuscript received: April 14, 2020 • Accepted: April 15, 2020 • Published online: April 29, 2020

\section{LETTER TO THE EDITOR}

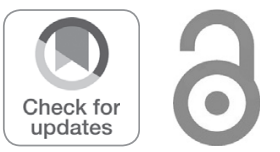

\section{ABSTRACT}

Stay-at-home mandates and quarantines related to the coronavirus (COVID-19) pandemic have led to greatly increased participation in online gaming. Initiatives such as \#PlayApartTogether that promote gaming for socializing and stress reduction may achieve positive outcomes. Although gaming can be a healthy coping strategy for the majority, it can also pose risks to some vulnerable individuals. Protracted periods of social isolation and technology-based activity pose the danger of solidifying unhealthy lifestyle patterns, leading to difficulties to readaptation when the COVID-19 crisis has passed. Balanced and effective approaches to gaming during the COVID-19 pandemic are needed to support physical and psychological wellbeing.
\end{abstract}

\section{KEYWORDS}

COVID-19, coronavirus, pandemic, screen time, gaming disorder, addiction

The coronavirus (COVID-19) pandemic has significantly disrupted normal activities globally. Stay-at-home mandates and quarantines have increased consumption of digital entertainment, particularly online gaming and related activities (e.g., esports viewing and videogame streaming) (Javed, 2020; Perez, 2020). For example, Verizon, a US-based telecommunications provider, reported a $75 \%$ increase in online gaming activity coinciding with initial stay-at-home directives (Pantling, 2020). In Italy, a 70\% increase in Fortnite-gamingrelated Internet traffic was reported (Lepido \& Rolander, 2020). Steam, a leading gaming distributor, reported more than 20 million concurrent active users, the most in its 16-year history, and live-streaming platforms YouTube Gaming and Twitch reported 10\% increase in viewership (Stephen, 2020). Thus far, increased online gaming has been perceived as complementary to public health efforts to promote spatial distancing (Abel \& McQueen, 2020; Businesswire, 2020). Notably, the World Health Organization (WHO) has seemingly expressed support for the gaming industry's online social media campaign (\#PlayApartTogether) that incorporates WHO messaging about coronavirus prevention guidelines in conjunction with encouraging online gaming (Ghebreyesus, 2020; Maden, 2020), although recent WHO mental health information (\#HealthyAtHome - Mental Health) recommends balanced screen time and gaming (WHO, 2020).

Online gaming may indeed enrich people's lives (Granic, Lobel, \& Engels, 2014). Initiatives such as \#PlayApartTogether that promote gaming for socializing and stress reduction may achieve positive outcomes. Research evidence shows that high involvement in gaming is not necessarily problematic (Király, Tóth, Urbán, Demetrovics, \& Maraz, 2017), and that for most, gaming appears adaptive (Billieux, Flayelle, Rumpf, \& Stein, 2019) and may reduce loneliness (Carras et al., 2017). Moreover, gaming is typically less 
harmful than many other potential behaviors used to cope with stress and aversive emotions, such as alcohol and drug use (Corbin, Farmer, \& Nolen-Hoekesma, 2013) or overeating (Razzoli, Pearson, Crow, \& Bartolomucci, 2017). Gaming may also be relatively inexpensive for those already owning gaming equipment.

However, it is important to acknowledge that significant increases in gaming may not always be beneficial and may pose risks for vulnerable individuals including minors and those affected by and at risk of gaming disorder (King, Koster, \& Billieux, 2019). Recognized negative impacts of excessive gaming, including harm to mental health, sleep patterns or physical health (Saunders et al., 2017), may be difficult to discern due to the imposition of work/schoolat-home practices. Protracted periods of isolation, technology-based activity, and limited face-to-face interaction have the danger of solidifying unhealthy lifestyle patterns, intensifying technology-related disorders and leading to difficulties to readaptation when the COVID-19 crisis has passed.

A further concern is that, if some individuals may develop, increase, or relapse into unhealthy patterns of gaming to relieve pandemic-related stress, self-isolation restrictions may inhibit help-seeking and present barriers for those in treatment. For this reason, we encourage the exploration of online/telehealth options, including ones that promote social connections (Addiction Policy Forum, 2020). It may also be important to make recommendations about the types of videogames that may better facilitate psychological and physical health, including those that encourage physical activity and social interaction and collaboration.

In summary, it is important to recognize that online gaming, while beneficial in moderation during this crisis, may also generate or promote vulnerabilities that could be exploited by industries that may see opportunities to promote their products (King \& Gaming Industry Response Consortium, 2018). Thus, it is important to devise and promote balanced and effective approaches to gaming during the COVID-19 pandemic to support physical and psychological wellbeing.

Funding sources: This work received financial support from a Discovery Early Career Researcher Award (DECRA) DE170101198 funded by the Australian Research Council (ARC).

Authors' contribution: Author DLK wrote the first draft of the letter and all authors contributed to and have approved the final manuscript.

Conflict of interest: The authors report no conflicts of interest. The authors alone are responsible for the content and writing of the paper.

\section{REFERENCES}

Abel, T., \& McQueen, D. (2020). The COVID-19 pandemic calls for spatial distancing and social closeness: Not for social distancing! International Journal of Public Health. http://doi. org/10.1007/s00038-020-01366-7.

Addiction Policy Forum. (2020). Free smartphone app offering telehealth support for those struggling with addiction during COVID-19. Retrieved from https://www.addictionpolicy.org/ post/free-smartphone-app-offering-telehealth-support-forthose-struggling-with-addiction-during-covid- 19.

Billieux, J., Flayelle, M., Rumpf, H. J., \& Stein, D. J. (2019). High involvement versus pathological involvement in video games: A crucial distinction for ensuring the validity and utility of gaming disorder. Current Addiction Reports, 6, 323-330.

Businesswire. (2020). Games industry unites to promote World Health Organization messages against COVID-19; Launch \#PlayApartTogether campaign. Retrieved March 31, 2020, from https://www.businesswire.com/news/home/20200328005018/ en/Games-Industry-Unites-Promote-World-HealthOrganization.

Carras, M. C., Van Rooij, A. J., Van de Mheen, D., Musci, R., Xue, Q. L., \& Mendelson, T. (2017). Video gaming in a hyperconnected world: A cross-sectional study of heavy gaming, problematic gaming symptoms, and online socializing in adolescents. Computers in Human Behavior, 68, 472-479.

Corbin, W. R., Farmer, N. M., \& Nolen-Hoekesma, S. (2013). Relations among stress, coping strategies, coping motives, alcohol consumption and related problems: A mediated moderation model. Addictive Behaviors, 38(4), 1912-1919.

Ghebreyesus, T. A. (2020). Thank you @RaymondChambers for mobilizing the gaming industry to feature @WHO advice on \#COVID19 to their users. We must all \#PlayApartTogether to beat the \#coronavirus. 9:29am. 29 March 2020. Tweet.

Granic, I., Lobel, A., \& Engels, R. C. (2014). The benefits of playing video games. American Psychologist, 69(1), 66-78.

Javed, J. (2020). eSports and gaming industry thriving as video games provide escape from reality during coronavirus pandemic. Retrieved from: https://www.wfaa.com/article/ sports/esports-gaming-industry-thriving-as-video-gamesprovide-escape-from-reality-during-coronavirus-pandemic/ 287-5953d982-d240-4e2b-a2ba-94dd60a8a383.

King, D.L. \& Gaming Industry Response Consortium. (2018). Comment on the global gaming industry's statement on ICD11 gaming disorder: A corporate strategy to disregard harm and deflect social responsibility? Addiction,113, 2145-2146.

King, D., Koster, E., \& Billieux, J. (2019). Study what makes games addictive. Nature, 573, 346-346.

Király, O., Tóth, D., Urbán, R., Demetrovics, Z., \& Maraz, A. (2017). Intense video gaming is not essentially problematic. Psychology of Addictive Behaviors, 31, 807-817.

Lepido, D. \& Rolander, N. (2020). Housebound Italian kids strain network with Fortnite marathon. Retrieved from: https://www. 
bloomberg.com/news/articles/2020-03-12/housebound-italiankids-strain-network-with-fortnite-marathon.

Maden, A. (2020). World Health Organization encourages people to game during coronavirus outbreak. Retrieved March 31, 2020, from https://www.windowscentral.com/world-healthorganization-encourages-people-game-during-coronavirusoutbreak.

Pantling, A. (2020). Gaming usage up 75 percent amid coronavirus outbreak, Verizon reports. Retrieved from https://www. hollywoodreporter.com/news/gaming-usage-up-75-percentcoronavirus-outbreak-verizon-reports-1285140.

Perez, M. (2020). Video games are being played at record levels as the coronavirus keeps people indoors. Retrieved from https:// www.forbes.com/sites/mattperez/2020/03/16/video-games-arebeing-played-at-record-levels-as-the-coronavirus-keepspeople-indoors/\#70eb644e57ba.
Razzoli, M., Pearson, C., Crow, S., \& Bartolomucci, A. (2017). Stress, overeating, and obesity: Insights from human studies and preclinical models. Neuroscience \& Biobehavioral Reviews, 76, 154-162.

Saunders, J. B., Hao, W., Long, J., King, D. L., Mann, K., FauthBühler, M., (2017). Gaming disorder: Its delineation as an important condition for diagnosis, management, and prevention. Journal of Behavioral Addictions, 6, 271-279.

Stephen, B. (2020). This is Twitch's moment [internet]. Retrieved from https://www.theverge.com/2020/3/18/21185114/twitchyoutube-livestreaming-streamelements-coronavirusquarantine-viewership-numbers.

World Health Organization. (2020). \#HealthyAtHome - Mental Health. Retrieved from https://www.who.int/news-room/ campaigns/connecting-the-world-to-combat-coronavirus/ healthyathome/healthyathome-mental-health. 